\title{
Neuron-glia interaction as a possible glue to translate the mind-brain gap: a novel multi-dimensional approach toward psychology and psychiatry
}

\author{
Takahiro A. Kato ${ }^{1,2 *}$, Motoki Watabe ${ }^{3}$ and Shigenobu Kanba ${ }^{1}$ \\ 1 Department of Neuropsychiatry, Graduate School of Medical Sciences, Kyushu University, Fukuoka, Japan \\ 2 Innovation Center for Medical Redox Navigation, Kyushu University, Fukuoka, Japan \\ ${ }^{3}$ Department of Management, School of Business, Monash University, Sunway, Malaysia
}

\section{Edited by:}

Stefan Borgwardt, University of Basel, Switzerland

Reviewed by:

R. Bruce Bolster, University of Winnipeg, Canada

Gianluca Serafini, Sapienza University of Rome, Italy

Gabriele Ende, Central Institute of

Mental Health, Germany

\section{*Correspondence:}

Takahiro A. Kato, Department of

Neuropsychiatry, Graduate School of

Medical Sciences, Kyushu University;

Innovation Center for Medical Redox

Navigation, Kyushu University, 3-1-1

Maidashi Higashi-ku, Fukuoka

812-8582, Japan

e-mail: takahiro@npsych.med.

kyushu-u.ac.jp
Neurons and synapses have long been the dominant focus of neuroscience, thus the pathophysiology of psychiatric disorders has come to be understood within the neuronal doctrine. However, the majority of cells in the brain are not neurons but glial cells including astrocytes, oligodendrocytes, and microglia. Traditionally, neuroscientists regarded glial functions as simply providing physical support and maintenance for neurons. Thus, in this limited role glia had been long ignored. Recently, glial functions have been gradually investigated, and increasing evidence has suggested that glial cells perform important roles in various brain functions. Digging up the glial functions and further understanding of these crucial cells, and the interaction between neurons and glia may shed new light on clarifying many unknown aspects including the mind-brain gap, and conscious-unconscious relationships. We briefly review the current situation of glial research in the field, and propose a novel translational research with a multi-dimensional model, combining various experimental approaches such as animal studies, in vitro \& in vivo neuron-glia studies, a variety of human brain imaging investigations, and psychometric assessments.

Keywords: translational research, neuron-glia interaction, mind-brain gap, unconscious, neuropsychoanalysis

\section{INTRODUCTION}

Neurons and synapses have long been the dominant focus of neuroscience, thus the pathophysiology of psychiatric disorders has come to be understood within the neuronal doctrine. However, the majority of cells in the brain are not neurons but glial cells including astrocytes, oligodendrocytes, and microglia. Traditionally, neuroscientists regarded glial functions as simply providing physical support and maintenance for neurons. Thus, in this limited role glia had been long ignored (1). Recently, glial functions have been gradually investigated, and increasing evidence has suggested that glial cells perform important roles in various brain functions. Digging up the glial functions and further understanding of these crucial cells, and the interaction between neurons and glia may shed new light on clarifying many unknown aspects including the mind-brain gap, and conscious-unconscious relationships. In addition, glial pathophysiology may explain the possible implications for the pathogenesis of major psychiatric disorders. The complexity of these aspects has yet to be well investigated. To explore these physiological and pathological aspects, novel translational methods should be applied with a multi-dimensional approach. Herein, we will briefly review the current situation of glial research in the field, and propose a novel translational research with a multi-dimensional model, combining various experimental approaches such as animal studies, in vitro \& in vivo neuronglia studies, a variety of human brain imaging investigations, and psychological/psychiatric assessments.

\section{GLIAL ROLES AND PATHOLOGY IN PSYCHIATRIC DISORDERS}

Recent biological studies have been revealing the important roles of glial cells in the process of neuropsychiatric disorders.

\section{ASTROCYTES}

Astrocytes are the most prevalent cell type in human brain and contribute to the homeostasis of the brain by regulation of neuronal metabolism, modulation of CNS inflammation, and direct/indirect synaptic transmission such as MNDA receptors (2, 3). Astrocyte dysfunction has been critical for various neurological disorders (4). Recent studies have shown abnormal expression of glial fibrillary acid protein (GFAP) - a prototypical marker of astrocyte - in postmortem brain of patients with schizophrenia and major affective disorders (5-7). In addition, recent rodent studies have suggested that astrocytes modulate anxious and depressive behaviors $(8,9)$. On the other hand, direct modulating effects of antidepressants have also been revealed (10-13). Thus, astrocytes have been supposed to be a novel therapeutic target against various psychiatric disorders such as major affective disorders and bipolar disorders $(14,15)$.

\section{OLIGODENDROCYTES}

Oligodendrocytes contribute to brain development and homeostasis in the brain by formulating myelin around axons, supporting neuronal networks in the brain. Recently, novel oligodendrocyte functions have been revealed such as monitoring neuronal 
activities via myelin-forming oligodendrocytes (16) and modulating the conduction velocity of action potentials along axons in the rat hippocampus (17). Dysfunctions of oligodendrocytes have been indicated in psychiatric disorders, especially schizophrenia and major affective disorders, from a series of genetic studies $(18,19)$, postmortem studies $(20-22)$, and diffusion tensor imaging (DTI) studies (23-27). A novel animal model of schizophrenia has been developed by treating a copper chelator, which induces oligodendrocyte dysfunction and white matter abnormality as demyelination and schizophrenia-related behaviors $(28,29)$. Cuprizone caused marked behavioral changes (working memory deficit) indicated by the results of Y-maze task, which showed an increase in the number of arm entries and a decrease in alternation behavior. These cuprizone-induced behavioral changes were effectively prevented by chronic administration of quetiapine, an atypical antipsychotic, which also diminished demyelination (28). On the other hand, recent rodent studies have revealed the interaction between oligodendrocyte dysfunction and social behaviors. Makinodan et al. reported that oligodendrocyte dysfunction is formed by early-period social isolation and this maladaptive environment induces working memory deficit associated with prefrontal cortex (PFC) function in later life (30). Liu et al. reported that protracted social isolation of adult mice induces behavioral, transcriptional, and ultrastructural changes in oligodendrocytes of the PFC and impairs adult myelination (31).

\section{MICROGLIA}

Microglia are unique glial cells of mesodermal origin in the brain that act as "brain macrophage"; immunological/inflammatory players by moving around and releasing cytokines and free radicals $(32,33)$. Thus, microglia have proved to play important roles in various brain pathologies such as neurodegenerative diseases and neuropathic pain via inducing inflammation and oxidative stress (34-36). Recently, microglia have been revealed to have direct contact with synapses and have proved to play crucial roles in neuronal development through synaptic pruning (3739). Postmortem studies have shown microglial activation in the brain of patients with schizophrenia and major affective disorders, especially suicide victims (40-42). In addition, positron emission tomography (PET) imaging studies using the peripheral benzodiazepine receptor bindings has shown that microglia are activated in patients with schizophrenia (43-45) and autism (46). On the other hand, minocycline, an antibiotic with inhibitory effects on microglial cells, has been reported to have therapeutic effects on schizophrenia and unipolar psychotic depression (47-49). In addition, rodent in vitro studies have proved the novel effect of psychotropic drugs (atypical antipsychotics such as risperidone and aripiprazole, and antidepressants such as paroxetine and sertraline, both selective serotonin reuptake inhibitors) directly on microglia by suppressing release of inflammatory cytokines and free radicals (50-54). Thus, microglia are suggested to play key roles in psychiatric disorders $(53,55,56)$.

In the brain, neurons, astrocytes, oligodendrocytes, and microglia are mutually communicating with each other, by directcontacting or via neurotransmitters and other various small molecules (57), and dysfunction of neuron-glia communication may induce pathological conditions not only in neurodegenerative diseases (58) but also in psychiatric conditions such as psychosis, depression, and anxiety. The above-mentioned recent findings strongly suggest that glial cells contribute to psychiatric disorders, while the underlying mechanisms have not been clarified.

\section{POSSIBLE GLIAL ROLES IN HUMAN MENTAL FUNCTIONS}

Until recently, the actual roles of glia in mental activities, especially for healthy humans, have not been investigated. As the first step to clarify this unexplored field, we have started to conduct a series of social decision-making experiments with healthy human subjects using minocycline, a microglial inhibitor (59-61). Healthy Japanese adult males made a monetary decision about whether or not to trust an anonymous partner after a 4-day oral administration of minocycline. Our first trial revealed that the minocycline group showed a positive correlation between their monetary score in trust game and their evaluation scores of others' trustworthiness in a questionnaire (Yamagishi's General Trust Scale), but surprisingly the placebo group did not (60). It would be rational to consider the monetary and questionnaire score to be positively correlated because both scores measure the other's trustworthiness, but there was no positive correlation with the placebo group. The questionnaire is measuring only conscious-level decision-making, on the other hand the monetary score is measuring the final decision-making affected by not only the conscious but also the unconscious; suggesting that some unconscious noisy factors seem to be affecting the placebo group. Treatment with minocycline, a microglial inhibitor, has shown the positive correlation. Therefore, this first trial has indicated that microglial activation may cause "unconscious noises" against appropriate social decisionmaking, and inhibiting microglial activity may reduce such noise (60). In a next trial with larger samples, we additionally measured the effects of anxiety and personality as candidates for "noise" factors, by using Temperament and Character Inventory (TCI) and State-Trait Anxiety Inventory (STAI) (59). The monetary score in trust game was significantly lower in the minocycline group. Interestingly, participants' ways of decision-making were significantly shifted; certain personality traits (cooperativeness, reward dependence, and self-directedness) proved to be the main modulating factors of decision-making in the placebo group, on the other hand the minocycline group was mainly modulated by state anxiety and trustworthiness. Our results of the second trial suggest that minocycline led to more situation-oriented decision-making, possibly by suppressing the effects of personality traits, and furthermore that personality and social behaviors might be modulated by microglia. Interestingly, cooperativeness has proved to be the most influential factor in the process of decision-making in the placebo group of Japanese participants (59). It is widely known that cooperativeness and cooperative behaviors have been highly respected and emphasized aspects in Japanese society. Thus, of course, these aspects are ingrained during childhood by various sociocultural experiences within family relationships, schools, and other areas of society in Japan. Early-life events may activate human microglia, establish a certain neurosynaptic connection, and this formation may determine personality and personality-oriented social behaviors in later life $(59,62)$. If these experiments are conducted in other countries with different sociocultural backgrounds, other personality traits may be identified. 
In addition, we have recently reported a possible outcome that minocycline, a microglial inhibitor, also reduces the risk of the "honey trap" during economic exchanges between males $\times$ females (61). Males tend to cooperate with physically attractive females without careful evaluation of their trustworthiness. In our experiment, young healthy male participants made risky choices (whether or not to trust female partners, identified only by photograph, who had decided in advance to exploit the male participants). The results show that trusting behavior in male participants significantly increased in relation to the perceived attractiveness of the female partner, but attractiveness did not impact trusting behavior in the minocycline group (61). These novel effects of minocycline may highlight the unknown roles microglia play in deeper human mental activities; microglia may modulate our unconscious drives in various social settings. The abovementioned findings shed new light on the dark side of microglial social/mental functions in humans, especially highlighting the role of microglia for the unconscious. In the same way that Sigmund Freud, the founder of psychoanalysis, proposed that our behaviors must be controlled by the unconscious world, microglia may unconsciously control our behaviors. How do microglia act as fundamental mediators between the conscious and the unconscious world? What do neurobiological mechanisms justify their eventual role in bridging the gap between neuroscience and psychoanalysis? Answers to the above questions are not yet clear, but we have recently proposed a hypothesis creating a link between Freud's unconscious drives such as the death drive and microglial activation (62). For example, microglial maladaptive over-activation in a certain brain region may activate human aggressive behaviors as a result of destructive drives [For the details, please see our recent article; Ref. (62)]. In the brain, not only microglia but also other glia such as astrocytes and oligodendrocytes exist, thus complicated neuron-glia interactions may modulate our mental activities including the unconscious (Figure 1). Further research should be applied to clarify these unresolved questions.

After Freud's theory of unconscious roles in behaviors which was initially identified in the 1980s (63), Pribram and his colleagues have developed this theory in terms of a better articulated model of neural computation $(64,65)$. In addition, recent neuropsychoanalytic movements have been updating Freud's theory with modern sophisticated methods of cognitive neuroscience (66-72). Thus, these recent approaches have been revealing the underlying mechanisms of implicit processing in a variety of information-processes including the social processes using rodent experiments. At present, the link underlying mechanisms between neuron-glia interactions and the conscious-unconscious relationship is largely unsolved, and few experimental methods have been developed to test these unknown brain mechanisms at either the microscopic or macroscopic level. Unconscious processing needs to be given a greater focus in terms of brain mechanisms. One possible solution is the novel ontogenetic approach; called "optogenetics” (73-76). Optogenetics is a revolutionary technique involving taking a light-activated gene (called a channel rhodopsin) targeted into a single neuron type. This technique enables to clarify direct interaction between activation of specific neuron in specific region by light and the resulting outcomes such as behaviors and emotional reactions at rodent level. A recent study has interestingly

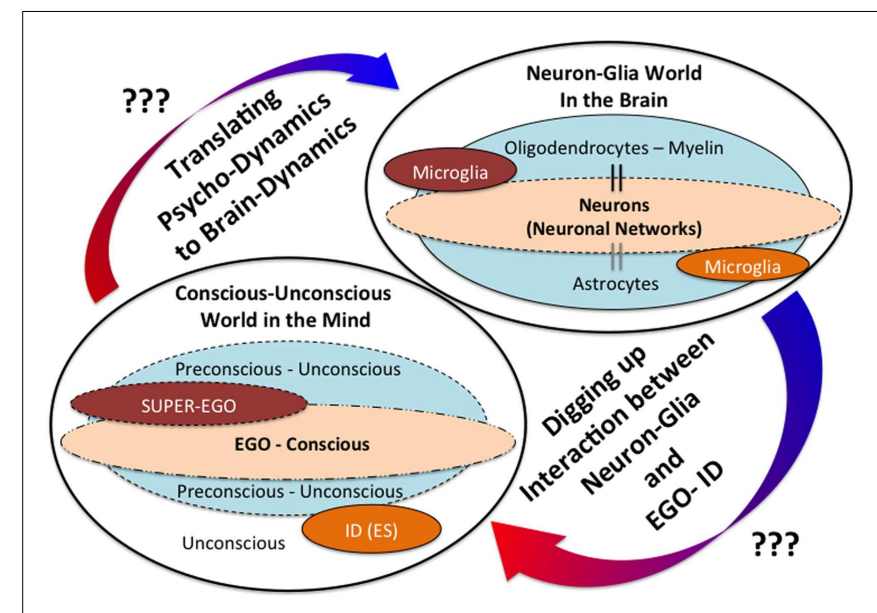

FIGURE 1 |The mind-brain gap from a novel glial neuropsychoanalytic perspective. The interaction between the mind and the brain has not been well understood. Freud, the founder of psychoanalysis, proposed the conception of mind structure models consisting of the following three components: the ID (unconscious/instinctual drives), the EGO (the exclusive apparatus of the conscious mind), and the SUPER-EGO (which represses the id in order to avoid any disruptions of rational thought). The existence and the significances of these mental components may be explained by future understandings of the neuron-glia interactions. The hypothetical interaction between the ID (unconscious drives) and microglia has already been proposed in our recent theoretical paper (62).

shown that activation of specific neurons in hippocampus produce a false memory in mice (77). Further technological developments in modulating glial cells by light and in activating both neurons and glial cells at the same time, by multiple fluorescent lights, may shed new light on resolving unknown roles of glia and neuron-glia interaction in behaviors and the conscious-unconscious. Functional roles and pathological contributions of astrocyte, oligodendrocyte, and/or microglia in conscious or unconscious processes have not been well understood, and we hypothesize that each cell may differently contribute to these physical and/or pathological processes in different brain regions such at the brainstem, limbic, or thalamocortical region, respectively. Future developments in optogenetics may clarify these unknown aspects.

\section{LIMITATION AND FUTURE PERSPECTIVES OF NEURO-GLIA RESEARCH ON PSYCHOLOGY AND PSYCHIATRY}

To explore the above-mentioned hypothesis, further translational research is needed. Several limitations should be made note of at the present stage. At first, rodent studies focusing on the unconscious are limiting. Even if the unconscious exists in rodents, it seems to be impossible to measure the unconscious in rodents devoid of human language capabilities. Therefore, to uncover the unconscious mechanisms, we have no alternative method except examining actual human subjects. We have no specific drugs to modulate glial cells utilized in human, and minocycline is reported to have other brain functions in addition to microglial inhibition $(78,79)$. On the other hand, some brain imaging techniques enable us to explore the unknown roles of glial cells such as DTI technique and PET imaging using the peripheral benzodiazepine receptor bindings, while the specificities of these imaging methods are not 
at satisfactory levels (80). On the other hand, we can reconsider previous findings of brain imaging experiments. Functional MRI ( $\mathrm{fMRI}$ ) is a brain imaging procedure measuring brain activity by detecting associated changes in blood flow $(81,82)$. Outcomes of fMRI have long been believed to monitor solely neuronal activities, because cerebral blood flow and neuronal activation have been thought to be almost equivalent. However, not only neuronal activities but also glial activities, especially astrocyte activities, rely on cerebral blood flow. Therefore, at least to some extent, brain activities expressed by fMRI may be showing a part of glial activation. In addition, MR spectroscopy (MRS) is one of the novel imaging approaches to measure dynamic brain functions focusing on metabolomics including glia-related molecules. For example, myo-inositol, which can be measured by MRS, is regarded as a marker of astrocyte activity (83). These imaging methods and combination of these imaging techniques may shed new light on clarifying unknown roles of glia in psychiatric disorders (84, 85). For example, activated microglia-derived myelin damage has been indicated in the pathophysiology of schizophrenia by rodent experimental models $(28,29,86,87)$, while it is not confirmed in human subjects. Combination of human DTI and PET may clarify the mutual interaction between microglial activation and myelin damage in schizophrenia patients. On the other hand, connectivity of each brain region has been important in the understanding of the roles of brain functions from the era of Hughlings Jackson. fMRI studies have revealed the importance of these aspects (88, 89 ), and the recent development of DTI is showing us the significance of more complicated brain networks focusing on not only neurons but also glial cells such as oligodendrocytes (90, 91).

Finally, we propose the multi-dimensional approach to clarify the underlying brain mechanisms of mental functions including the unconscious (Figure 2). Based on our discussion, we believe that not only neurons but also glial cells have a vital role in the process of mental activities, a novel approach focusing on neuron-glia interactions should be applied. Combination of brain imaging techniques focusing on both neurons and glial cells should be applied (24, 26, 27, 43-46, 92-94). The most significant limitation in human brain research is that we cannot obtain living brain cells, including glial cells, from living human subjects from an ethical perspective. Presently, we can apply an alternative method; human brain cells such as neuronal cells can be established from somatic cells (not from the brain) such as skin fibroblasts by utilizing the gene-modification technique of

\section{REFERENCES}

1. Miller G. Neuroscience.
The dark side of glia. Sci-
ence (2005) 308:778-81.
doi:10.1126/science.308.5723.778
2. Halassa MM, Fellin T, Haydon PG.
The tripartite synapse: roles for glio-
transmission in health and disease.
Trends Mol Med (2007) 13:54-63.
doi:10.1016/j.molmed.2006.12.005
3. Sofroniew MV, Vinters HV. Astro-
cytes: biology and pathology. Acta
Neuropathol (2010) 119:7-35. doi:
10.1007/s00401-009-0619-8

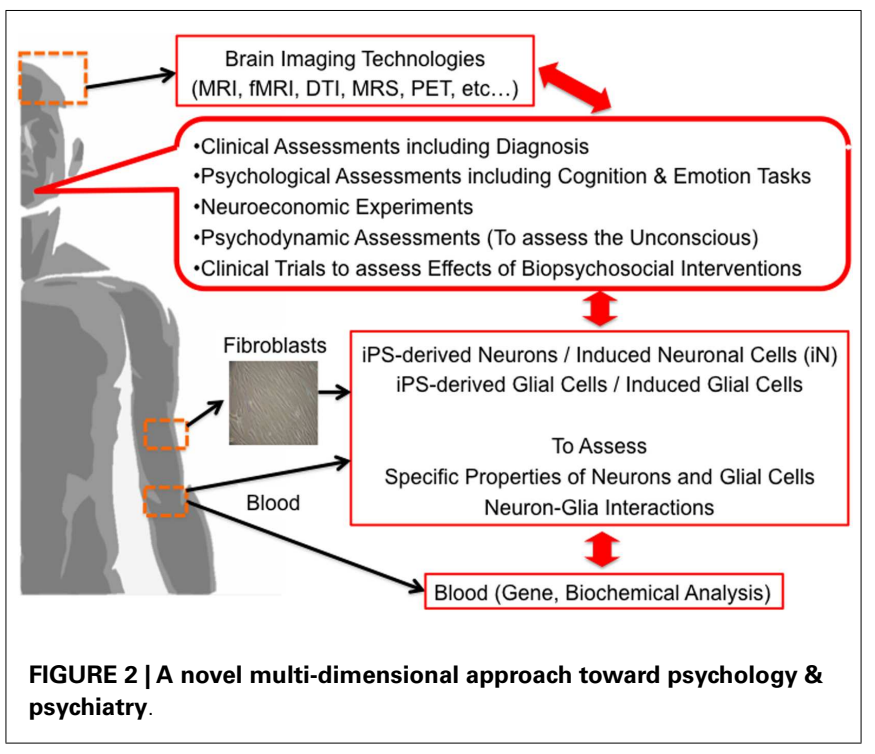

induced pluripotent stem (iPS) cells. In addition, recently, neuronal cells are more easily established from directly conversion of human skin fibroblasts, called induced neuronal (iN) cells (95-99). Novel methods of establishing glial cells are strongly warranted based on iPS or direct conversion techniques in the near future. Multi-dimensional aspects of same human subjects, from genes, blood, brain imaging, psychometrics, social function, unconscious functions, psychodynamic assessments to molecular functions of somatic tissue-derived neuronal and glial cells, should be investigated and analyzed together (Figure 2). This approach may explore the novel roles of glial cells in various human mental activities including the unconscious. The application of this method for psychiatric patients should also be encouraged in the establishment of novel diagnostic methods and novel therapies.

\section{ACKNOWLEDGMENTS}

This work was supported by Grant-in-Aid for Scientific Research on (1) Innovative Areas "Glia Assembly" (No. 25117011) of The Ministry of Education, Culture, Sports, Science, and Technology, Japan, (2) the Japan Society for the Promotion of Science (No. 24650227), and (3) the Health and Labor Sciences Research Grant No. [H 24-Seishin-Jitsuyouka (Seishin)-Ippan-001].
6. Feresten AH, Barakauskas V, Ypsilanti A, Barr AM, Beasley CL. Increased expression of glial fibrillary acidic protein in prefrontal cortex in psychotic illness. Schizophr Res (2013) 150(1):252-7. doi: 10.1016/j.schres.2013.07.024

7. Rajkowska G, Stockmeier CA. Astrocyte pathology in major depressive disorder: insights from human postmortem brain tissue. Curr Drug Targets (2013) 14(11):1225-36. doi:10.2174/ 13894501113149990156
8. Cao X, Li LP, Wang Q, Wu $\mathrm{Q}, \mathrm{Hu} \mathrm{HH}$, Zhang $\mathrm{M}$, et al. Astrocyte-derived ATP modulates depressive-like behaviors. Nat Med (2013) 19:773-7. doi:10.1038/nm. 3162

9. Quesseveur G, David DJ, Gaillard MC, Pla P, Wu MV, Nguyen $\mathrm{HT}$, et al. BDNF overexpression in mouse hippocampal astrocytes promotes local neurogenesis and elicits anxiolytic-like activities. Transl Psychiatry (2013) 3:e253. doi:10.1038/ tp. 2013.30 
10. Hashioka S. Antidepressants and neuroinflammation: can antidepressants calm glial rage down? Mini Rev Med Chem (2011) 11:555-64. doi:10.2174/138955711795906888

11. Hisaoka K, Tsuchioka M, Yano R, Maeda N, Kajitani N, Morioka $\mathrm{N}$, et al. Tricyclic antidepressant amitriptyline activates fibroblast growth factor receptor signaling in glial cells: involvement in glial cell line-derived neurotrophic factor production. I Biol Chem (2011) 286:21118-28. doi:10.1074/ jbc.M111.224683

12. Kajitani N, Hisaoka-Nakashima K, Morioka N, Okada-Tsuchioka M, Kaneko M, Kasai M, et al. Antidepressant acts on astrocytes leading to an increase in the expression of neurotrophic/growth factors: differential regulation of FGF-2 by noradrenaline. PLoS One (2012) 7:e51197. doi:10.1371/ journal.pone.0051197

13. Kittel-Schneider S, Kenis G, Schek J, Van Den Hove D, Prickaerts J, Lesch KP, et al. Expression of monoamine transporters, nitric oxide synthase 3 , and neurotrophin genes in antidepressant-stimulated astrocytes. Front Psychiatry (2012) 3:33. doi:10.3389/fpsyt.2012.00033

14. Steiner J, Bogerts B, Sarnyai Z, Walter M, Gos T, Bernstein HG, et al. Bridging the gap between the immune and glutamate hypotheses of schizophrenia and major depression: potential role of glial NMDA receptor modulators and impaired blood-brain barrier integrity. World J Biol Psychiatry (2012) 13:482-92. doi:10.3109/15622975.2011.583941

15. Sanacora G, Banasr M. From pathophysiology to novel antidepressant drugs: glial contributions to the pathology and treatment of mood disorders. Biol Psychiatry (2013) 73:1172-9. doi:10.1016/j.biopsych. 2013.03.032

16. Micu I, Ridsdale A, Zhang L, Woulfe J, Mcclintock J, Brantner $\mathrm{CA}$, et al. Real-time measurement of free $\mathrm{Ca} 2+$ changes in CNS myelin by two-photon microscopy. Nat Med (2007) 13:874-9. doi:10.1038/ nm1568

17. Yamazaki Y, Hozumi Y, Kaneko K, Sugihara T, Fujii S, Goto K, et al. Modulatory effects of oligodendrocytes on the conduction velocity of action potentials along axons in the alveus of the rat hippocampal CA1 region. Neuron Glia Biol (2007) 3:325-34. doi:10.1017/ S1740925X08000070

18. Tkachev D, Mimmack ML, Ryan MM, Wayland M, Freeman T,
Jones PB, et al. Oligodendrocyte dysfunction in schizophrenia and bipolar disorder. Lancet (2003) 362:798-805. doi:10.1016/ S0140-6736(03)14289-4

19. McCullumsmith RE, Gupta D, Beneyto M, Kreger E, Haroutunian V, Davis KL, et al. Expression of transcripts for myelinationrelated genes in the anterior cingulate cortex in schizophrenia. Schizophr Res (2007) 90:15-27. doi:10. 1016/j.schres.2006.11.017

20. Uranova NA, Vostrikov VM, Orlovskaya DD, Rachmanova VI. Oligodendroglial density in the prefrontal cortex in schizophrenia and mood disorders: a study from the Stanley Neuropathology Consortium. Schizophr Res (2004) 67:269-75. doi:10.1016/S09209964(03)00181-6

21. Uranova NA, Vostrikov VM, Vikhreva OV, Zimina IS, Kolomeets NS, Orlovskaya DD. The role of oligodendrocyte pathology in schizophrenia. Int $J$ Neuropsychopharmacol (2007) 10:537-45. doi:10.1017/S1461145707007626

22. Bernstein HG, Steiner J, Bogerts B. Glial cells in schizophrenia: pathophysiological significance and possible consequences for therapy. Expert Rev Neurother (2009) 9:1059-71. doi:10.1586/ern.09.59

23. Price SJ, Jena R, Burnet NG, Hutchinson PJ, Dean AF, Pena A, et al. Improved delineation of glioma margins and regions of infiltration with the use of diffusion tensor imaging: an image-guided biopsy study. AJNR Am J Neuroradiol (2006) 27:1969-74.

24. Schlosser RG, Nenadic I, Wagner G, Gullmar D, Von Consbruch K, Kohler S, et al. White matter abnormalities and brain activation in schizophrenia: a combined DTI and fMRI study. Schizophr Res (2007) 89:1-11. doi:10.1016/j.schres.2006. 09.007

25. Miyata J, Hirao K, Namiki C, Fujiwara $H$, Shimizu M, Fukuyama $\mathrm{H}$, et al. Reduced white matter integrity correlated with corticosubcortical gray matter deficits in schizophrenia. Schizophr Res (2009) 111:78-85. doi:10.1016/j. schres.2009.03.010

26. Kubota M, Miyata J, Yoshida H, Hirao K, Fujiwara H, Kawada R, et al. Age-related cortical thinning in schizophrenia. Schizophr Res (2011) 125:21-9. doi:10.1016/j. schres.2010.10.004

27. Kubota M, Miyata J, Sasamoto A, Sugihara G, Yoshida H, Kawada R, et al. Thalamocortical disconnection in the orbitofrontal region associated with cortical thinning in schizophrenia. JAMA Psychiatry (2013) 70:12-21. doi:10.1001/ archgenpsychiatry.2012.1023

28. Xiao L, Xu H, Zhang Y, Wei Z, He J, Jiang W, et al. Quetiapine facilitates oligodendrocyte development and prevents mice from myelin breakdown and behavioral changes. $\mathrm{Mol}$ Psychiatry (2008) 13:697-708. doi: 10.1038/sj.mp.4002064

29. Zhang Y, Xu H, Jiang W, Xiao L, Yan B, He J, et al. Quetiapine alleviates the cuprizone-induced white matter pathology in the brain of C57BL/6 mouse. Schizophr Res (2008) 106:182-91. doi:10.1016/j. schres.2008.09.013

30. Makinodan M, Rosen KM, Ito S, Corfas G. A critical period for social experience-dependent oligodendrocyte maturation and myelination. Science (2012) 337:1357-60. doi:10.1126/science.1220845

31. Liu J, Dietz K, Deloyht JM, Pedre X, Kelkar D, Kaur J, et al. Impaired adult myelination in the prefrontal cortex of socially isolated mice. $\mathrm{Nat}$ Neurosci (2012) 15:1621-3. doi:10. 1038/nn.3263

32. Block ML, Zecca L, Hong JS. Microglia-mediated neurotoxicity: uncovering the molecular mechanisms. Nat Rev Neurosci (2007) 8:57-69. doi:10.1038/nrn2038

33. Hanisch UK, Kettenmann $\mathrm{H}$. Microglia: active sensor and versatile effector cells in the normal and pathologic brain. Nat Neurosci (2007) 10:1387-94. doi:10.1038/nn1997

34. Graeber MB, Streit WJ. Microglia: biology and pathology. Acta Neuropathol (2010) 119:89-105. doi:10. 1007/s00401-009-0622-0

35. Inoue K, Tsuda M. Microglia and neuropathic pain. Glia (2009) 57:1469-79. doi:10.1002/glia.20871

36. Kettenmann H, Hanisch UK, Noda M, Verkhratsky A. Physiology of microglia. Physiol Rev (2011) 91:461-553. doi:10.1152/physrev.00011.2010

37. Wake H, Moorhouse AJ, Jinno S, Kohsaka S, Nabekura J. Resting microglia directly monitor the functional state of synapses in vivo and determine the fate of ischemic terminals. J Neurosci (2009) 29:3974-80. doi:10.1523/ JNEUROSCI.4363-08.2009

38. Paolicelli RC, Bolasco G, Pagani F, Maggi L, Scianni M, Panzanelli P, et al. Synaptic pruning by microglia is necessary for normal brain development. Science (2011) 333:1456-8. doi:10.1126/science. 1202529
39. Schafer DP, Lehrman EK, Kautzman AG, Koyama R, Mardinly AR, Yamasaki R, et al. Microglia sculpt postnatal neural circuits in an activity and complementdependent manner. Neuron (2012) 74:691-705. doi:10.1016/j.neuron. 2012.03.026

40. Radewicz K, Garey LJ, Gentleman SM, Reynolds R. Increase in HLA-DR immunoreactive microglia in frontal and temporal cortex of chronic schizophrenics. J Neuropathol Exp Neurol (2000) 59:137-50.

41. Steiner J, Mawrin C, Ziegeler A, Bielau $\mathrm{H}$, Ullrich $\mathrm{O}$, Bernstein HG, et al. Distribution of HLADR-positive microglia in schizophrenia reflects impaired cerebral lateralization. Acta Neuropathol (2006) 112:305-16. doi:10.1007/ s00401-006-0090-8

42. Steiner J, Bielau H, Brisch R, Danos P, Ullrich O, Mawrin C, et al. Immunological aspects in the neurobiology of suicide: elevated microglial density in schizophrenia and depression is associated with suicide. J Psychiatr Res (2008) 42:151-7. doi:10.1016/j.jpsychires. 2006.10.013

43. van Berckel BN, Bossong $\mathrm{MG}$, Boellaard R, Kloet R, Schuitemaker A, Caspers E, et al. Microglia activation in recent-onset schizophrenia: a quantitative (R)[11C]PK11195 positron emission tomography study. Biol Psychiatry (2008) 64:820-2. doi:10.1016/j.biopsych.2008.04.025

44. Doorduin J, De Vries EF, Willemsen AT, De Groot JC, Dierckx RA, Klein HC. Neuroinflammation in schizophrenia-related psychosis: a PET study. J Nucl Med (2009) 50:1801-7. doi:10. 2967/jnumed.109.066647

45. Takano A, Arakawa R, Ito H, Tateno A, Takahashi H, Matsumoto R, et al. Peripheral benzodiazepine receptors in patients with chronic schizophrenia: a PET study with [11C]DAA1106. Int J Neuropsychopharmacol (2010) 13:943-50. doi:10.1017/S1461145710000313

46. Suzuki K, Sugihara G, Ouchi Y, Nakamura K, Futatsubashi M, Takebayashi K, et al. Microglial activation in young adults with autism spectrum disorder. JAMA Psychiatry (2013) 70:49-58. doi:10.1001/jamapsychiatry.2013. 272

47. Levkovitz Y, Mendlovich S, Riwkes $\mathrm{S}$, Braw $\mathrm{Y}$, Levkovitch-Verbin $\mathrm{H}$, Gal G, et al. A double-blind, randomized study of minocycline for 
the treatment of negative and cognitive symptoms in early-phase schizophrenia. J Clin Psychiatry (2010) 71:138-49. doi:10.4088/JCP. 08m04666yel

48. Chaudhry IB, Hallak J, Husain N, Minhas F, Stirling J, Richardson P, et al. Minocycline benefits negative symptoms in early schizophrenia: a randomised double-blind placebocontrolled clinical trial in patients on standard treatment. $J$ Psychopharmacol (2012) 26:1185-93. doi:10.1177/0269881112444941

49. Miyaoka T, Wake R, Furuya M, Liaury K, Ieda M, Kawakami K, et al. Minocycline as adjunctive therapy for patients with unipolar psychotic depression: an open-label study. Prog Neuropsychopharmacol Biol Psychiatry (2012) 37:222-6. doi:10.1016/j.pnpbp.2012.02.002

50. Kato T, Monji A, Hashioka S, Kanba S. Risperidone significantly inhibits interferon-gamma-induced microglial activation in vitro. Schizophr Res (2007) 92:108-15. doi:10. 1016/j.schres.2007.01.019

51. Kato T, Mizoguchi Y, Monji A, Horikawa H, Suzuki SO, Seki Y, et al. Inhibitory effects of aripiprazole on interferon-gamma-induced microglial activation via intracellular $\mathrm{Ca} 2+$ regulation in vitro. $\mathrm{J} \mathrm{Neu}$ rochem (2008) 106:815-25. doi:10. 1111/j.1471-4159.2008.05435.x

52. Horikawa H, Kato TA, Mizoguchi Y, Monji A, Seki Y, Ohkuri T, et al. Inhibitory effects of SSRIs on IFN-gamma induced microglial activation through the regulation of intracellular calcium. Prog Neuropsychopharmacol Biol Psychiatry (2010) 34:1306-16. doi:10.1016/j. pnpbp.2010.07.015

53. Kato TA, Monji A, Mizoguchi Y, Hashioka S, Horikawa H, Seki Y, et al. Anti-inflammatory properties of antipsychotics via microglia modulations: are antipsychotics a "fire extinguisher" in the brain of schizophrenia? Mini Rev Med Chem (2011) 11:565-74. doi:10. 2174/138955711795906941

54. Kato TA, Monji A, Yasukawa K, Mizoguchi Y, Horikawa H, Seki $\mathrm{Y}$, et al. Aripiprazole inhibits superoxide generation from phorbol-myristate-acetate (PMA)stimulated microglia in vitro: implication for antioxidative psychotropic actions via microglia. Schizophr Res (2011) 129:172-82. doi:10.1016/j.schres.2011.03.019

55. Monji A, Kato T, Kanba S. Cytokines and schizophrenia: microglia hypothesis of schizophrenia. Psychiatry Clin Neurosci (2009)
63:257-65. doi:10.1111/j.14401819.2009.01945.x

56. Kato TA, Yamauchi Y, Horikawa H, Monji A, Mizoguchi Y, Seki Y, et al. Neurotransmitters, psychotropic drugs and microglia: clinical implications for psychiatry. Curr Med Chem (2013) 20:331-44. doi:10. 2174/0929867311320030003

57. Verkhratsky A, Kirchhoff F. Glutamate-mediated neuronalglial transmission. J Anat (2007) 210:651-60. doi:10.1111/j.14697580.2007.00734.x

58. Gibson GE, Starkov A, Blass JP, Ratan RR, Beal MF. Cause and consequence: mitochondrial dysfunction initiates and propagates neuronal dysfunction, neuronal death and behavioral abnormalities in age-associated neurodegenerative diseases. Biochim Biophys Acta (2010) 1802:122-34. doi:10.1016/j. bbadis.2009.08.010

59. Kato TA, Watabe M, Tsuboi $S$, Ishikawa K, Hashiya K, Monji A, et al. Minocycline modulates human social decision-making: possible impact of microglia on personalityoriented social behaviors. PLoS One (2012) 7:e40461. doi:10.1371/ journal.pone.0040461

60. Watabe M, Kato TA, Monji A, Horikawa H, Kanba S. Does minocycline, an antibiotic with inhibitory effects on microglial activation, sharpen a sense of trust in social interaction? Psychopharmacology (2012) 220:551-7. doi:10. 1007/s00213-011-2509-8

61. Watabe M, Kato TA, Tsuboi S, Ishikawa K, Hashiya K, Monji A, et al. Minocycline, a microglial inhibitor, reduces "honey trap" risk in human economic exchange. $\mathrm{Sci}$ Rep (2013) 3:1685. doi:10.1038/ srep01685

62. Kato TA, Kanba S. Are microglia minding us? Digging up the unconscious mind-brain relationship from a neuropsychoanalytic approach. Front Hum Neurosi (2013) 7:13. doi:10.3389/fnhum. 2013.00013

63. Freud S. Project for a scientific psychology. In: Strachey J, editor. The Standard Edition of the Complete Psychological Works of Sigmund Freud, Volume I (1886-1899): Pre-Psycho-Analytic Publications and Unpublished Drafts. London: The Hogarth Press (1950/1895). p. 281-391.

64. Pribram KH, Gill MM. Freud's "Project" Re-assessed. London: Hutchinson (1976).

65. Pribram KH. Freud's "project" and the mind-brain issue. J Nerv Ment
Dis (1978) 166:743-52. doi:10. 1097/00005053-197810000-00008

66. Fonagy P. Attachment Theory and Psychoanalysis. New York: Other Press (2001).

67. Solms M, Lechevalier B. Neurosciences and psychoanalysis. Int $J$ Psychoanal (2002) 83:233-7. doi:10. 1516/X9LD-JPCE-KKDR-BPU5

68. Solms M, Turnbull O. The Brain and the Inner World: An Introduction to the Neuroscience of Subjective Experience. New York: Other Press (2002).

69. Panksepp J. Neuro-psychoanalysis may enliven the mindbrain sciences. Cortex (2007) 43:1106-7. doi:10. 1016/S0010-9452(08)70714-7 discussion 1116-1121,

70. Arminjon M, Ansermet F, Magistretti P. The homeostatic psyche: Freudian theory and somatic markers. J Physiol Paris (2010) 104:272-8. doi:10.1016/j. jphysparis.2010.08.006

71. Northoff G. Neuropsychoanalysis in Practice: Brain, Self and Objects. New York: Oxford University Press (2011).

72. Panksepp J, Solms M. What is neuropsychoanalysis? Clinically relevant studies of the minded brain. Trends Cogn Sci (2012) 16:6-8. doi: 10.1016/j.tics.2011.11.005

73. Boyden ES, Zhang F, Bamberg E, Nagel G, Deisseroth K. Millisecondtimescale, genetically targeted optical control of neural activity. Nat Neurosci (2005) 8:1263-8. doi:10. 1038/nn1525

74. Deisseroth K, Feng G, Majewska AK, Miesenbock G, Ting A, Schnitzer MJ. Next-generation optical technologies for illuminating genetically targeted brain circuits. J Neurosci (2006) 26:10380-6. doi:10.1523/JNEUROSCI.3863-06. 2006

75. Zhang F, Wang LP, Brauner M, Liewald JF, Kay K, Watzke N, et al. Multimodal fast optical interrogation of neural circuitry. Nature (2007) 446:633-9. doi:10. 1038/nature05744

76. Deisseroth K. Optogenetics. Nat Methods (2011) 8:26-9. doi:10. 1038/nmeth.f.324

77. Ramirez S, Liu X, Lin PA, Suh J, Pignatelli M, Redondo RL, et al. Creating a false memory in the hippocampus. Science (2013) 341:387-91. doi:10.1126/ science. 1239073

78. Hashimoto K, Ishima T. A novel target of action of minocycline in NGF-induced neurite outgrowth in PC12 cells: translation initiation [corrected] factor eIF4AI. PLoS
One (2010) 5:e15430. doi:10.1371/ journal.pone.0015430

79. Garrido-Mesa N, Zarzuelo A, Galvez $\mathrm{J}$. What is behind the non-antibiotic properties of minocycline? Pharmacol Res (2013) 67:18-30. doi:10. 1016/j.phrs.2012.10.006

80. Lavisse S, Guillermier M, Herard AS, Petit F, Delahaye M, Van Camp N, et al. Reactive astrocytes overexpress TSPO and are detected by TSPO positron emission tomography imaging. $\mathrm{J} \mathrm{Neu}$ rosci (2012) 32:10809-18. doi:10. 1523/JNEUROSCI.1487-12.2012

81. Ogawa S, Lee TM, Kay AR, Tank DW. Brain magnetic resonance imaging with contrast dependent on blood oxygenation. Proc Natl Acad Sci U S A (1990) 87:9868-72. doi:10.1073/ pnas.87.24.9868

82. Raichle ME, Macleod AM, Snyder AZ, Powers WJ, Gusnard DA, Shulman GL. A default mode of brain function. Proc Natl Acad Sci U S A (2001) 98:676-82. doi:10.1073/ pnas.98.2.676

83. Chang L, Munsaka SM, Kraft-Terry S, Ernst T. Magnetic resonance spectroscopy to assess neuroinflammation and neuropathic pain. J Neuroimmune Pharmacol (2013) 8:576-93. doi:10.1007/s11481-0139460- $\mathrm{x}$

84. Rothermundt M, Ohrmann P, Abel S, Siegmund A, Pedersen A, Ponath $\mathrm{G}$, et al. Glial cell activation in a subgroup of patients with schizophrenia indicated by increased S100B serum concentrations and elevated myo-inositol. Prog Neuropsychopharmacol Biol Psychiatry (2007) 31:361-4. doi:10.1016/j. pnpbp.2006.09.013

85. Ende G, Hermann D, Demirakca T, Hoerst M, Tunc-Skarka N, WeberFahr W, et al. Loss of control of alcohol use and severity of alcohol dependence in non-treatmentseeking heavy drinkers are related to lower glutamate in frontal white matter. Alcohol Clin Exp Res (2013) 37:1643-9. doi:10.1111/acer.12149

86. Wergeland S, Torkildsen O, Myhr KM, Mork SJ, Bo L. The cuprizone model: regional heterogeneity of pathology. APMIS (2012) 120:648-57. doi:10.1111/j.16000463.2012.02882.x

87. Seki Y, Kato TA, Monji A, Mizoguchi Y, Horikawa H, Sato-Kasai M, et al. Pretreatment of aripiprazole and minocycline, but not haloperidol, suppresses oligodendrocyte damage from interferon- $\gamma$-stimulated microglia in co-culture model. Schizophr Res (2013) (in press). doi: 10.1016/j.schres.2013.09.011 
88. Biswal B, Yetkin FZ, Haughton VM, Hyde JS. Functional connectivity in the motor cortex of resting human brain using echo-planar MRI. Magn Reson Med (1995) 34: 537-41. doi:10.1002/mrm. 1910340409

89. Damoiseaux JS, Rombouts SA, Barkhof F, Scheltens P, Stam CJ, Smith SM, et al. Consistent restingstate networks across healthy subjects. Proc Natl Acad Sci U S A (2006) 103:13848-53. doi:10.1073/ pnas.0601417103

90. Toosy AT, Ciccarelli O, Parker GJ, Wheeler-Kingshott CA, Miller $\mathrm{DH}$, Thompson AJ. Characterizing function-structure relationships in the human visual system with functional MRI and diffusion tensor imaging. Neuroimage (2004) 21:1452-63. doi:10.1016/j. neuroimage.2003.11.022

91. Greicius MD, Supekar K, Menon V, Dougherty RF. Restingstate functional connectivity reflects structural connectivity in the default mode network. Cereb Cortex (2009) 19:72-8. doi:10.1093/cercor/bhn059
92. Denier N, Walter M, Bendfeldt $\mathrm{K}$, Lang U, Borgwardt S. Resting state abnormalities in psychosis compared to acute cannabinoids and opioids challenges: a systematic review of functional imaging studies. Curr Pharm Des (2012) 18:5081-92. doi:10.2174/ 138161212802884717

93. Jung WH, Borgwardt S, Fusar-Poli P, Kwon JS. Gray matter volumetric abnormalities associated with the onset of psychosis. Front Psychiatry (2012) 3:101. doi:10.3389/fpsyt. 2012.00101

94. Smieskova R, Allen P, Simon A, Aston J, Bendfeldt K, Drewe J, et al. Different duration of at-risk mental state associated with neurofunctional abnormalities. Hum Brain Mapp (2012) 33:2281-94. doi:10. 1002/hbm. 21360

95. Vierbuchen T, Ostermeier A, Pang ZP, Kokubu Y, Sudhof TC, Wernig M. Direct conversion of fibroblasts to functional neurons by defined factors. Nature (2010) 463:1035-41. doi:10.1038/nature08797

96. Pang ZP, Yang N, Vierbuchen T, Ostermeier A, Fuentes DR, Yang TQ, et al. Induction of human neuronal cells by defined transcription factors. Nature (2011) 476:220-3. doi: 10.1038/nature10202

97. Pfisterer U, Kirkeby A, Torper O, Wood J, Nelander J, Dufour A, et al. Direct conversion of human fibroblasts to dopaminergic neurons. Proc Natl Acad Sci U S A (2011) 108:10343-8. doi:10.1073/ pnas.1105135108

98. Qiang L, Fujita R, Yamashita T, Angulo S, Rhinn $\mathrm{H}$, Rhee $\mathrm{D}$, et al. Directed conversion of Alzheimer's disease patient skin fibroblasts into functional neurons. Cell (2011) 146:359-71. doi:10. 1016/j.cell.2011.07.007

99. Yoo AS, Sun AX, Li L, Shcheglovitov A, Portmann T, Li Y, et al. MicroRNA-mediated conversion of human fibroblasts to neurons. Nature (2011) 476:228-31. doi:10. 1038/nature10323

Conflict of Interest Statement: The authors declare that the research was conducted in the absence of any commercial or financial relationships that could be construed as a potential conflict of interest.

Received: 20 August 2013; accepted: 07 October 2013; published online: 21 October 2013.

Citation: Kato TA, Watabe Mand Kanba $S$ (2013) Neuron-glia interaction as a possible glue to translate the mindbrain gap: a novel multi-dimensional approach toward psychology and psychiatry. Front. Psychiatry 4:139. doi: 10.3389/fpsyt.2013.00139

This article was submitted to Neuropsychiatric Imaging and Stimulation, a section of the journal Frontiers in Psychiatry.

Copyright (c) 2013 Kato, Watabe and Kanba. This is an open-access article distributed under the terms of the Creative Commons Attribution License (CC BY).

The use, distribution or reproduction in other forums is permitted, provided the original author(s) or licensor are credited and that the original publication in this journal is cited, in accordance with accepted academic practice. No use, distribution or reproduction is permitted which does not comply with these terms. 